With 1 plate

Printed in Great Britain

\title{
An Appraisal of Caryophanon latum
}

\author{
By P. J. PROVOST* and R. N. DOETSCH \\ Departments of Microbiology and Dairy Science, University of Maryland, \\ College Park, Maryland, U.S.A.
}

(Received 25 September 1961)

\begin{abstract}
SUMMARY
Cultures of the giant bacterium Caryophanon latum Peshkoff, among them our own isolates from cow dung, were studied. A method for isolation is described. A fluid medium containing acid-hydrolysed casein, thiamine, biotin, sodium acetate, sodium butyrate and dipotassium phosphate, at $\mathrm{pH} 7 \cdot 8$, was devised which, without added colloids, allowed luxuriant growth of $C$. latum when sufficient aeration was provided. $C$. latum has been found to utilize acetic, butyric and $\beta$-hydroxybutyric acids. A variety of other carbon sources did not appear to be readily utilized by C. latum. The organism produced a carotenoid-like yellow pigment, the synthesis of which was inhibited by diphenylamine. A large amount of poly- $\beta$-hydroxybutyric acid (PHB) was synthesized by $C$. latum growing in the fluid medium described above. Much of the PHB was liberated as free granules. C. latum was found to be Gram-positive, in contrast to previously published reports.
\end{abstract}

\section{INTRODUCTION}

The giant bacterium Caryophanon latum is $3 \mu$ wide $\times 15 \mu$ long, as an average. Although a number of papers concerning its cytology have appeared (Peshkoff, 1940, 1946; Pringsheim \& Robinow, 1947; DeLamater, 1952; Bisset, 1953; Sall \& Mudd, 1955; Tomesik \& Grace, 1955; Murray, 1957), there is little information about the ecology, nutrition and basic physiology. C. latum was first described by Peshkoff (1940); it was isolated from cow dung and was cultivated on manure extract agar but not on 'ordinary' media. Pringsheim \& Robinow (1947) re-isolated C. latum from cow dung, presented a definitive description of its structure, and contributed materially toward an understanding of its ecology and nutrition. The organism did not appear to be an inhabitant of the bovine intestine. It could be grown on an agar medium (PYA) containing $0.5 \%(\mathrm{w} / \mathrm{v})$ Bacto peptone, $0.5 \%$ $(\mathrm{w} / \mathrm{v})$ Bacto-yeast extract, and $0.01 \%(\mathrm{w} / \mathrm{v})$ sodium acetate, at $\mathrm{pH} \mathbf{7 \cdot 4}$ to $7 \cdot 6$, but grew poorly, if at all, in fluid media unless these were supplemented with small amounts of agar. The first report of an effort to grow $C$. latum with defined nutrients was published by May \& Gershenfeld (1955). These workers used a medium containing soluble sodium silicate, hydrolysed cellulose, salts, asparagine and pantothenic acid. Weeks \& Kelley (1958) were not able to grow $C$. latum well in fluid media (PYA less agar) even with the incorporation of various types of particulate matter.

* Present address : Department of Microbiology, School of Medicine, University of Maryland, Baltimore 1, Maryland, U.S.A. 
Somewhat better growth was obtained in cow-dung extract fluid medium. The present work reappraises some parts of previous studies and supplies new information about the nutrition and physiology of Caryophanon latum.

\section{METHODS}

Isolation of Caryophanon latum cultures. Intensive efforts to isolate C. latum from nature were made only with cow dung as source material. Relatively fresh (from a few hours to one day old) cow dung samples were collected from pastures, barns and pens. These samples upon return to the laboratory were incubated for one day at room temperature (about $20^{\circ}$ ) in glass bottles with loose screw tops. Wet mount preparations were then examined microscopically $(\times 440)$ for typical C. latum trichomes. Most samples thus examined did not show C. latum. However, some positive samples were found; isolations of $C$. latum were made from dung samples found in close association with hay and straw, and from a pasture dung sample.

For isolation, a positive sample was divided into two parts; one part was autoclaved $\left(121^{\circ}, 15 \mathrm{~min}.\right)$ and inoculated with several loopsful of the remaining portion. After incubation for $24 \mathrm{hr}$. at $25^{\circ}$, the inoculated dung teemed with Caryophanon latum trichomes; a cultural enrichment was thus obtained. C. latum appeared to grow somewhat better in cow dung than most other bacteria present in the inoculum. The enriched sample was suspended in water (about $2 \mathrm{~g}$. in $10 \mathrm{ml}$.), and the suspension forced through several layers of gauze to remove large particles. The filtrate was centrifuged at $50 \mathrm{~g}$ for $8 \mathrm{~min}$., the sediment resuspended in water and recentrifuged as many as 11 times, with discard of the supernatant fluid each time. A mechanical enrichment of the relative numbers of C. latum was achieved because the large trichomes sedimented with this low-speed processing. The resulting sediment was streaked on plates of PYA medium (Pringsheim \& Robinow, 1947). After $24 \mathrm{hr}$. at $25^{\circ}$, the plates were examined microscopically for minute colonies of the granular greenish appearance typical of C. latum; twelve cultures were isolated and purified by continued streaking.

Cultures were obtained from the American Type Culture Collection (Washington, D.C., U.S.A.; ATCC 12871 and ATCC 13872), Dr E. G. Pringsheim (Göttingen University, Germany), and Dr T. Gibson (University of Edinburgh); these cultures, with our own isolates, formed the collection on which the work reported here was based. The cultures were maintained on PYA slopes at $4^{\circ}$ and transferred at monthly intervals.

Standard procedures. All fluid cultures were incubated at $25^{\circ}$ on a rotary shaker (about $200 \mathrm{rev} . / \mathrm{min}$.) to provide vigorous aeration. For tube cultures, racks were constructed which held up to 50 tubes $\left(16 \times 150 \mathrm{~mm}\right.$.) at an angle of about $40^{\circ}$ from horizontal and which could be clamped to the shaker platform.

Inocula were prepared by suspending organisms from PYA slopes grown for $24 \mathrm{hr}$. at $25^{\circ}$, in $5 \mathrm{ml}$. water or fluid medium. Four $\mathrm{ml}$. were removed and the organisms washed (3 times in vitamin requirement studies, once or twice in most other experiments), with centrifugation periods of $5 \mathrm{~min}$. at $500 \mathrm{~g}$. The washed organisms were finally resuspended in a volume of $4 \mathrm{ml}$. (optical density at $500 \mathrm{~m} \mu$ about $0 \cdot 2)$. Inocula were added to fluid media at $1 \%(\mathrm{v} / \mathrm{v})$ of the medium volume. 
Turbidimetric measurements were made with a Bausch \& Lomb ('Spectronic 20' colorimeter, at $625 \mathrm{~m} \mu$ in coloured media and at $500 \mathrm{~m} \mu$ in colourless media. Optically matched $16 \times 150 \mathrm{~mm}$. Pyrex culture tubes were used in growth experiments.

Dry-weight determinations were made with $3 \mathrm{ml}$. samples in tared glass cups held at $90-100^{\circ}$ for $24 \mathrm{hr}$. and cooled over $\mathrm{CaCl}_{2}$ before weighing.

Sterilization of fluid media was usually done with $0 \cdot 45 \mu$ pore diameter membrane filters (Millipore Filter Corp., Bedford, Mass., U.S.A.).

The following staining procedures were used: the Hucker modification of the Gram stain and the Burdon lipid stain (Manual of Microbiological Methods, 1957), and a negative stain with an aqueous $7 \%(\mathrm{w} / \mathrm{v})$ filtered suspension of nigrosin.

Nutritional studies. A fluid medium was developed containing: 1\% (w/v) 'saltfree' acid-hydrolysed casein (Hy-Case SF, Sheffield Chem. Co., Norwich, N.Y., U.S.A.); $0.5 \%(\mathrm{w} / \mathrm{v})$ sodium acetate, anhydrous; $0.5 \%(\mathrm{w} / \mathrm{v})$ sodium butyrate; $0 \cdot 1 \%(\mathrm{w} / \mathrm{v}) \mathrm{K}_{2} \mathrm{HPO}_{4} ; \mathrm{pH} \mathrm{7 \cdot 8-7 \cdot 9}$. When supplemented with a mixture of B-vitamins, this medium supported good growth of Caryophanon latum. Aqueous solutions of the B-vitamins were prepared at $\times 100$ the final desired medium concentrations (see Table 1 for final concentrations) and added to or individually deleted from the above basal medium. Growth responses were measured turbidimetrically. PYA medium, without added agar, and the defined medium of May \& Gershenfeld (1955) were also examined for ability to suport the growth of $C$. latum.

Utilization of carbon and energy sources. The ability of Caryophanon latum to utilize a variety of carbon compounds was tested by measuring growth responses when these compounds were added to a basal medium incapable of supporting growth unless supplemented with a utilizable carbon and energy source. The basal medium contained: $1 \%(\mathrm{w} / \mathrm{v}) \mathrm{Hy}$-Case SF; $0 \cdot 1 \%(\mathrm{w} / \mathrm{v}) \mathrm{K}_{2} \mathrm{HPO}_{4}$; thiamine $\mathrm{HCl}$ $0 \cdot 2 \mathrm{mg}$./1.; biotin 0.04 mg./l.; pH 7.8-7.9. This basal medium is referred to as CHB.

Sodium acetate and sodium butyrate, sterilized in aqueous solution by membrane filtration, were tested at various concentrations. Carbohydrates, sterilized with ethylene oxide, were added to CHB medium at $0.5 \%(w / v)$. The $\mathrm{C}_{5}-\mathrm{C}_{9}$ saturated fatty acids (as sodium salts, sterilized by autoclaving) were tested at final concentrations of $0 \cdot 2 \%(\mathrm{w} / \mathrm{v})$. Tricarboxylic acid cycle and related compounds (formate, pyruvate, propionate, oxaloacetate, malate, $\alpha$-ketoglutarate, fumarate, succinate; as sodium salts, sterilized both by membrane filtration or autoclaving) were added to $\mathrm{CHB}$ medium at $0.02 \mathrm{M}$ to detect utilization. In later work, 'sparker' concentrations of acetate and butyrate $(0.025 \% \mathrm{w} / \mathrm{v})$ were incorporated into CHB medium for retesting the ability of Caryophanon latum strain 1.8 to utilize glucose, pyruvate, caproate and $\alpha$-ketoglutarate.

To detect oxygen uptake on the sodium salts of the $\mathrm{C}_{2}-\mathrm{C}_{9}$ saturated fatty acids by resting suspensions of Caryophanon latum, conventional Warburg equipment was used. Each flask contained $3 \cdot 1 \mathrm{ml}$. total fluid, consisting of: $2 \mu$ mole of fatty acid (Na salt) in $0 \cdot 1 \mathrm{ml}$. water, $1 \mathrm{ml}$. 0.067 M-phosphate buffer (pH 7.5), $1 \mathrm{ml}$. of washed suspension of organism (equivalent to about $1.3 \mathrm{mg}$. dry wt.); $0.9 \mathrm{ml}$. water; $0.1 \mathrm{ml}$. of $20 \%(\mathrm{w} / \mathrm{v}) \mathrm{KOH}$ in the centre well containing a piece of fluted filter paper. The temperature of the water bath was maintained at $24 \cdot 9^{\circ}$. The resting organisms were used as soon as prepared, with no starvation period.

Pigment studies. Four-day cultures in CHM medium (100 ml.) were harvested 
and washed twice in $\mathbf{0 . 8 5} \%(\mathrm{w} / \mathrm{v}) \mathrm{NaCl}$. A concentrated suspension $(2 \mathrm{ml}$.) was spread on filter paper and dried over $\mathrm{CaCl}_{2}$. (Extraction with acetone removed most of the pigment.) The dried organisms were extracted with $50 \mathrm{ml}$. boiling methanol for 5 min., the extracts filtered (Whatman no. 50 paper) and their optical density values from 230 to $700 \mathrm{~m} \mu$ at $10 \mathrm{~m} \mu$ intervals determined in a Beckman DU spectrophotometer $(1 \mathrm{~cm}$. silica cells, $3 \mathrm{ml}$. volume) with a methanol blank. Diphenylamine was incorporated into CHM medium at $0.02-0 \cdot 10 \mathrm{mg} . / \mathrm{ml}$. medium to determine whether inhibition of pigment synthesis would occur. Methanol extracts were prepared and examined, as described above, from the amine-containing cultures.

Poly- $\beta$-hydroxybutyric acid $(\boldsymbol{P H B})$ studies. Washed CHM culture harvests were dried either in vacuo over $\mathrm{CaCl}_{2}$ or by lyophilization. The dried material was first extracted for several hours in a Soxhlet apparatus with anhydrous di-ethyl ether which removed yellow cell pigment and much lipid material, and then extracted to exhaustion with chloroform; the latter removed the PHB. Dry weights of chloroform extracts were determined by boiling away the chloroform from measured samples. Samples of crude extracts were tested for melting point and solubilities (see Williamson \& Wilkinson, 1958) and for absorption spectrum when dissolved in hot $\left(100^{\circ}\right)$ concentrated $\mathrm{H}_{2} \mathrm{SO}_{4}$ (Slepecky \& Law, 1960). An assay for the PHB in the extracts, similar to that of Law \& Slepecky (1961), but with the use of a crotonic acid standard curve, was performed. Crotonic acid used as the standard was purified by recrystallization from water three times.

The utilization of sodium- $\beta$-hydroxybutyrate by Caryophanon latum was determined by incorporating this compound $(0.02 \mathrm{M}$ and $0.5 \%, \mathrm{w} / \mathrm{v}$, membrane-filtered) into $\mathrm{CHB}$ medium and measuring growth responses turbidimetrically.

General studies. A solid medium containing acid-hydrolysed casein, yeast extract and sodium acetate (CYA, see Results) was used in determining the biochemical capacities of Caryophanon latum as concerns the production of catalase, reduction of nitrate $\left(0 \cdot 1 \%, \mathrm{w} / \mathrm{v}, \mathrm{KNO}_{3}\right.$ added), production of indole $(0 \cdot 1 \%, \mathrm{w} / \mathrm{v}$, DL-tryptophan added), and liquefaction of gelatin (agar replaced with $12 \% \mathrm{w} / \mathrm{v}$, gelatin). These tests were done as outlined in the Manual of Microbiological Methods (1957). Studies of the relation to oxygen (in deep shake tubes of CYA medium) and to culture survival on PYA slopes were also done.

The effect of lysozyme was tested on organisms suspended in an aqueous solution containing $7.5 \%(\mathrm{w} / \mathrm{v})$ polyethylene glycol, $0.01 \mathrm{M}-\mathrm{NaCl}, 0.005 \mathrm{M}-\mathrm{MgSO}_{4}$, and lysozyme $375 \mu \mathrm{g}$. $/ \mathrm{ml}$. at $\mathrm{pH} \mathbf{7 \cdot 6}$.

The effects of antibiotics and sulfa drugs ('Sensi-Discs', Baltimore Biological Laboratory, Inc., Baltimore, Md., U.S.A.) were tested on plates of PYA medium. The effects of crystal violet $(1 / 100,000)$ and sodium azide $(0.03 \%, w / v)$ were determined by incorporation of these compounds into PYA medium.

\section{RESULTS}

\section{Growth of Caryophanon latum in fluid media}

Table 1 shows typical results obtained in the vitamin-omission studies. Lessened growth of both Caryophanon latum cultures tested occurred only upon the omission of thiamine $\mathrm{HCl}$ and biotin. Thiamine $\mathrm{HCl}$ was required for growth. The requirement 
for biotin was not so clear-cut; some growth occurred when it was omitted, but this was accompanied by heavy clumping. Further testing, with thiamine $\mathrm{HCl}$ as the only vitamin added to the basal medium, showed (lower part of Table 1) that it alone could not satisfy the vitamin requirements of $C$. latum. The addition of biotin allowed luxuriant growth of both cultures, thus indicating a requirement for both thiamine HCL and biotin.

\title{
Table 1. Vitamin requirements of Caryophanon latum
}

\begin{abstract}
Growth responses are expressed as optical density values at $625 \mathrm{~m} \mu$. The basal medium contained $1 \%(\mathrm{w} / \mathrm{v}) \mathrm{Hy}$-Case SF, $0.5 \%(\mathrm{w} / \mathrm{v})$ each of sodium acetate and sodium butyrate, $0 \cdot 1 \%(\mathrm{w} / \mathrm{v}) \mathrm{K}_{2} \mathrm{HPO}_{4} ; \mathrm{pH} \mathrm{7 \cdot 8}$. Vitamins and concentrations were (mg./l.): $p$-aminobenzoic acid, 0.2 ; biotin, 0.04 ; folic acid, 0.04; cyanocobalamine, 0.015; Ca-D-pantothenate, 0.04 ; nicotinic acid, 0.2 ; pyridoxal $\mathrm{HCl}, 1 \cdot 0$; riboflavin, 0.2 ; thiamine $\mathrm{HCl}, 0.2$.
\end{abstract}

\begin{tabular}{|c|c|c|c|c|}
\hline \multirow[b]{3}{*}{ Vitamins omitted } & \multicolumn{4}{|c|}{ Culture } \\
\hline & \multicolumn{2}{|c|}{ Isolate 1.8} & \multicolumn{2}{|c|}{ ATCC 12871 } \\
\hline & $48 \mathrm{hr}$. & $96 \mathrm{hr}$. & $48 \mathrm{hr}$. & $96 \mathrm{hr}$. \\
\hline All & $0 \cdot 12$ & 0.08 & 0.01 & 0.02 \\
\hline None & $1 \cdot 03$ & 1.82 & $1 \cdot 15$ & $1 \cdot 22$ \\
\hline Thiamine $\mathbf{H C l}$ & $0 \cdot 14$ & $0 \cdot 12$ & 0.01 & $0 \cdot 02$ \\
\hline \multirow[t]{3}{*}{ Biotin } & $0 \cdot 48$ & 0.50 & $0 \cdot 80$ & $0 \cdot 88$ \\
\hline & \multicolumn{4}{|c|}{ Culture } \\
\hline & \multicolumn{2}{|c|}{ Isolate $\mathbf{1 . 8}$} & \multicolumn{2}{|c|}{ ATCC 12871 } \\
\hline Vitamins added & $48 \mathrm{hr}$. & $120 \mathrm{hr}$. & $48 \mathrm{hr}$. & $120 \mathrm{hr}$. \\
\hline None & 0.07 & 0.05 & $0 \cdot 01$ & 0.03 \\
\hline Thiamine $\mathbf{H C l}$ & 0.06 & 0.08 & 0.02 & 0.06 \\
\hline Thiamine $\mathrm{HCl}+$ biotin & $1 \cdot 18$ & 1.96 & 0.01 & $1 \cdot 66$ \\
\hline
\end{tabular}

With the addition of these two growth factors, a fluid medium (CHM) for the growth of Caryophanon latum was developed. It consisted of (in g./l.) Hy-Case, 10.0; sodium acetate, anhydrous, 5.0 ; sodium butyrate, $5.0 ; \mathrm{K}_{2} \mathrm{HPO}_{4}, \mathbf{1 . 0}$; and (in mg./l.) thiamine $\mathbf{H C l}, 0 \cdot 20$; and biotin $0 \cdot 04$; $\mathrm{pH} 7 \cdot 8-7 \cdot 9$. This medium was usually sterilized by filtration through an $0 \cdot 45 \mu$ pore diameter membrane filter, but it could be autoclaved $\left(121^{\circ}, 10 \mathrm{~min}\right.$.). Removal of acetate and butyrate from CHM medium resulted in a basal medium (CHB) which did not allow extensive growth of $C$. latum; CHB medium was used in the carbon and energy source utilization studies (see above).

Large crops of organism (2.0-2.5 g. dry wt./l. in $72 \mathrm{hr}$.) were produced in CHM medium with adequate aeration. Typical growth responses, of representative Caryophanon latum cultures in CHM medium, with and without aeration, are shown in Table 2. All cultures, except isolate 2.7, grew in the medium on continued transfer. Culture ATCC 12871 showed a rather long lag period which was characteristic of this culture when grown in CHM medium. The lag seemed to be overcome to some extent on continued transfer in CHM medium (Table 2). The addition of $0.1 \%(\mathrm{w} / \mathrm{v})$ Bacto yeast extract to CHM medium allowed the growth of culture isolate $2 \cdot 7$ and overcame the lag period of culture ATCC 12871. The addition of salts $\left(\mathrm{MgSO}_{4} .7 \mathrm{H}_{2} \mathrm{O}, 0.25 \mathrm{mg} . / \mathrm{ml} . ; \mathrm{MnSO}_{4} . \mathrm{H}_{2} \mathrm{O}, 0.01 \mathrm{mg} . / \mathrm{ml}\right.$. $; \mathrm{FeSO}_{4} \cdot 7 \mathrm{H}_{2} \mathrm{O}, 0.01 \mathrm{mg} . / \mathrm{ml}$. $)$ 
allowed the production of a more intense yellow pigmentation. The acid-hydrolysed casein in CHM medium could not be replaced with $0.5 \%(\mathrm{w} / \mathrm{v})\left(\mathrm{NH}_{4}\right)_{2} \mathrm{SO}_{4} ;$ no attempts were made to replace it with known amino acids and peptides.

Without vigorous aeration, none of the Caryophanon latum cultures grew well, even in CHM medium. Table 2 shows typical growth responses of still (non-shaken) cultures ( $5 \mathrm{ml}$. amounts in $16 \times 150 \mathrm{~mm}$. culture tubes).

Table 2. Growth of representative Caryophanon latum cultures upon serial transfer with vigorous aeration in $\mathrm{CHM}$ medium and growth in $\mathrm{CHM}$ medium without aeration

Figures in parentheses indicate day on which optical density shown was attained and also day when one loopful of culture was transferred to next set.

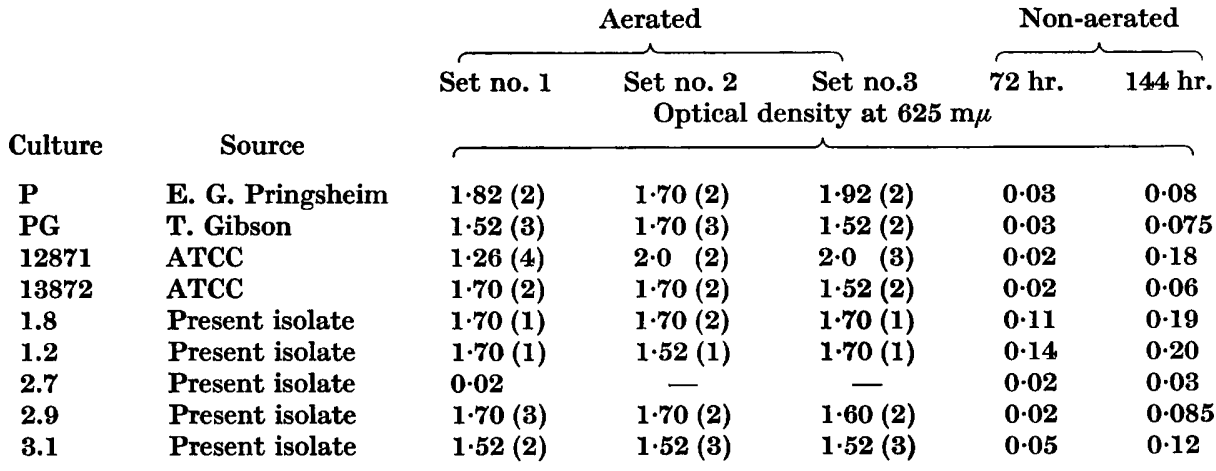

A solid medium (CYA) was developed for the routine culture of Caryophanon latum. This medium consisted of (in g./l.) Hy-Case SF, 10.0; Bacto yeast extract, 5.0; sodium acetate, anhydrous, 5.0; and agar, 15.0; $\mathrm{pH} \mathrm{7 \cdot 8-7 \cdot 9.}$

Considerably greater crops of organism were produced on this medium than on the PYA solid medium of Pringsheim \& Robinow (1947). The higher concentration of acetate $(0.5 \%, w / v)$ in the CYA medium (PYA contains only $0.01 \%, w / v)$ was probably responsible for the enhanced growth.

PYA medium, in a fluid form without added agar, did not yield large crops even with vigorous aeration. Maximum optical density values at $625 \mathrm{~m} \mu$ produced in this medium were in the range of $0 \cdot 30-0 \cdot 40$ with isolate 1.8 and ATCC 12871. Omission of the acetate $0.01 \%,(\mathrm{w} / \mathrm{v})$ did not markedly affect the amount of growth, suggesting that there was too little acetate in PYA medium to have much effect as an energy source.

A study of the effects of the nutrients in the defined medium of May \& Gershenfeld (1955) revealed the following. Asparagine $(0.5 \%, \mathrm{w} / \mathrm{v})$ could not replace the $\mathrm{Hy}$-Case SF of CHM medium. Asparagine + pantothenate $(0.04 \mathrm{mg} . / 1)+$. riboflavin (0.2 mg./l.) + salts (mg./ml.): $\mathrm{MgSO}_{4} \cdot 7 \mathrm{H}_{2} \mathrm{O}, 0 \cdot 25 ; \mathrm{KCl}, 0 \cdot 25 ; \mathrm{NnSO}_{4} \cdot \mathrm{H}_{2} \mathrm{O}, 0.01$; $\mathrm{FeSO}_{4} .7 \mathrm{H}_{2} \mathrm{O}, 0.01$ could not replace the $\mathrm{Hy}$-Case SF. Glucose $(0.5 \%$, w/v) could not substitute for the acetate and butyrate in CHM medium. It would appear that the defined medium of May \& Gershenfeld was not able to yield large crops of Caryophanon latum. Sodium silicate was not tested since the present work showed that $C$. latum did not require colloidal material for growth in fluid media. 


\section{Carbon and energy sources for Caryophanon latum}

Manometric studies (Table 3) showed that Caryophanon latum oxidized acetic and butyric acids, but not other saturated fatty acids. C. latum isolate 1.8 resting organisms, from growth in CHM medium supplemented with $0 \cdot 3 \%(\mathrm{w} / \mathrm{v})$ each of sodium caproate and heptanoate, showed no enhanced ability to oxidize the $\mathrm{C}_{5}-\mathrm{C}_{9}$ acids.

Table 3. Oxidation of fatty acids by resting suspensions of Caryophanon latum isolate 1.8

Flasks contained equiv. $1 \cdot 3 \mathrm{mg}$. dry wt. organisms harvested at $24 \mathrm{hr}$. from CHM medium, washed three times in $0.85 \%(\mathrm{w} / \mathrm{v}) \mathrm{NaCl}$ in water. The fatty acids were used as sodium salts.

\begin{tabular}{|c|c|c|}
\hline $\begin{array}{l}\text { Substrate } \\
(2 \mu \text { mole })\end{array}$ & $\begin{array}{c}\mu \mathrm{l} . \mathrm{O}_{2} \\
(5 \mathrm{hr} .)\end{array}$ & $\begin{array}{c}Q_{\mathrm{O}_{2}} \\
\text { (average } \mu \mathrm{l} . \mathrm{O}_{2} / \mathrm{mg} \text {. } \\
\text { dry wt. } / \mathrm{hr} . \text { ) }\end{array}$ \\
\hline None & $67 \cdot 5$ & $9 \cdot 4$ \\
\hline Acetate $\left(\mathrm{C}_{2}\right)$ & $138 \cdot 0$ & $19 \cdot 3$ \\
\hline Propionate $\left(\mathrm{C}_{3}\right)$ & $60 \cdot 5$ & $8 \cdot 5$ \\
\hline Butyrate $\left(\mathrm{C}_{4}\right)$ & $136 \cdot 0$ & $19 \cdot 1$ \\
\hline Valerate $\left(C_{5}\right)$ & 74.0 & $10 \cdot 3$ \\
\hline Caproate $\left(\mathbf{C}_{6}\right)$ & $81 \cdot 5$ & $11 \cdot 5$ \\
\hline Heptanoate $\left(\mathrm{C}_{7}\right)$ & $81 \cdot 0$ & $11 \cdot 3$ \\
\hline Octanoate $\left(\mathrm{C}_{8}\right)$ & $74 \cdot 5$ & $10 \cdot 4$ \\
\hline Pelargonate $\left(\mathbf{C}_{9}\right)$ & $67 \cdot 0$ & $9 \cdot 4$ \\
\hline
\end{tabular}

Table 4. Stimulation of growth of Caryophanon latum by acetate and butyrate

Figures in parentheses indicate day on which optical density shown was reached.

\begin{tabular}{|c|c|c|}
\hline \multirow[b]{2}{*}{ Addition to CHB medium* } & \multicolumn{2}{|c|}{ Organism } \\
\hline & Isolate 1.8 & ATCC 12871 \\
\hline & \multicolumn{2}{|c|}{ Max. turbidity (optical density at $625 \mathrm{~m} \mu$ ) } \\
\hline None & 0.005 & 0.005 \\
\hline $0 \cdot 05 \mathrm{M}$-sodium acetate & $0.62(2)$ & $1 \cdot 21(4)$ \\
\hline $0.05 \mathrm{M}$-sodium butyrate & $1 \cdot 70(6)$ & $2.0 \quad(5)$ \\
\hline
\end{tabular}

Of a variety of fatty acids, tricarboxylic acid cycle acids, carbohydrates and related compounds tested, only acetate and butyrate allowed substantial growth of Caryophanon latum when added to CHB medium. Table 4 shows typical responses of $C$. latum to acetate and butyrate. The concentrations $(0.05 \mathrm{M})$ are far in excess of the minimum amounts of these acids necessary for growth stimulation; namely, about $0.01 \mathrm{M}$. A stimulatory effect on butyrate utilization in the presence of acetate (Table 5) in isolate 1.8 was observed.

No substantial growth stimulation of isolate 1.8 or ATCC 12871 was provided by any of the following, added singly to $\mathrm{CHB}$ medium: $\mathrm{C}_{5}-\mathrm{C}_{9}$ saturated fatty acids at $0.2 \%(w / v)$ (some growth on the $\mathrm{C}_{5}$ and $\mathrm{C}_{6}$ acids with both cultures after 8-11-day lag periods); glycerol, arabinose, glucose, galactose, maltose, cellobiose, soluble starch at $0.5 \%(\mathrm{w} / \mathrm{v})$ each: formate, pyruvate, propionate, oxaloacetate, malate, $\alpha$-ketoglutarate, fumarate, succinate, all as sodium salts at $0.02 \mathrm{M}$ each (slight 
turbidities, $\mathrm{OD}=0.02-0.04$ at $625 \mathrm{~m} \mu$, were produced on malate, $\alpha$-ketoglutarate, fumarate). The addition of small amounts of acetate and butyrate $(0.025 \%, \mathrm{w} / \mathrm{v}$, each) to CHB medium and the subsequent testing of isolate 1.8 for growth on glucose, pyruvate, caproate, or $\alpha$-ketoglutarate (concentrations as above) showed apparent utilization of caproate and $\alpha$-ketoglutarate, but not glucose and pyruvate; this was deduced from the greater turbidities in the former than were produced in the low acetate + butyrate medium without supplementation.

Table 5. Stimulation of butyrate utilization by acetate with Caryophanon latum 1.8

\begin{tabular}{lccc}
\multicolumn{1}{c}{ Addition to CHB } & \multicolumn{3}{c}{ Optical density at $625 \mathrm{~m} \mu$} \\
\cline { 2 - 3 } & $24 \mathrm{hr}$. & $48 \mathrm{hr}$. & $144 \mathrm{hr}$. \\
None & 0.01 & 0.01 & 0.01 \\
$0.5 \%(w / v)$ sodium acetate & 0.37 & 0.80 & $0 \cdot 42$ \\
$0.5 \%(w / v)$ sodium butyrate & 0.02 & 0.02 & 1.73 \\
$0.5 \%(w / v)$ of both acetate and butyrate & 1.24 & 1.50 & 1.87
\end{tabular}

\section{Caryophanon latum pigment}

A yellow pigment was prominent with all organisms of our collection of Caryophanon latum when large crops were obtained. Diphenylamine inhibited the production of the pigment, but not growth of isolate 1.8 , at $0.02,0.04$ and $0.06 \mathrm{mg} . / \mathrm{ml}$. in CHM medium. Growth of culture ATCC 12871 was inhibited by lower concentrations of diphenylamine $(0.04 \mathrm{mg} . / \mathrm{ml}$.). Methanol extracts of 4-day CHM cultures of C. latum isolate 1.8 , grown with and without 0.02 or $0.04 \mathrm{mg}$. diphenylamine $/ \mathrm{ml}$., showed an absorption peak at $430 \mathrm{~m} \mu$ in the non-inhibited cultures but no strong absorption in this range in the inhibited cultures. From the absorption peak of the C. latum pigment and previous work (Ellinghausen \& Pelczar, 1957) which indicated diphenylamine to be an inhibitor of carotenoid pigment synthesis, it seems likely that the C. latum pigment is carotenoid.

\section{Poly- $\beta$-hydroxybutyric acid $(\boldsymbol{P H B})$ in Caryophanon latum}

Caryophanon latum cultures grown in CHM medium presented a cloudy opalescent supernatant portion on standing for several hours after removal from the shaker. Staining with basic dyes revealed no particulate matter in these supernatant fluids, but negative staining with nigrosin showed small spherical refractile granules (Pl. 1, fig. 1). These free granules did not stain well with the Burdon lipid material stain (Pl. 1, fig. 2). Intact $C$. latum trichomes settled to the bottom in still cultures, and thus were not responsible for the supernatant turbidity. The supernatant portion (mostly granules) of settled cultures could account for a large percentage (Table 6) of the particulate dry weight of CHM cultures. The free granule material (supernatant) increased rapidly about one day after the initial rise in culture turbidity. Analysis of chloroform extracts of CHM culture harvests revealed large amounts of a material with the properties of PHB as described by Williamson \& Wilkinson (1958) and with a peak absorption at $235 \mathrm{~m} \mu$ when dissolved in hot $\left(100^{\circ}\right)$ concentrated $\mathrm{H}_{2} \mathrm{SO}_{4}$ (Slepecky \& Law, 1960). Thus, it appeared that the supernatant granules were mainly PHB granules, probably liberated on lysis of the organisms. Table 6 also shows an assay for the PHB content of a 6-day CHM culture. 
The percentage PHB is higher than any previously reported; but it should be borne in mind that a considerable degree of lysis had occurred, thus decreasing the particulate dry weight due to organisms. Analysis of a 4-day CHM culture showed a PHB content of about $50 \%$.

The PHB appeared to be synthesized mainly from butyrate; but organisms grown only with acetate in CHB medium also showed some, though lesser, accumulation of lipid granules. The large synthesis of PHB in CHM medium may have reflected a high $\mathrm{C}: \mathbf{N}$ ratio in this medium. Increasing the Hy-Case $\mathrm{SF}$ content of CHM to $3 \%(w / v)$ did not diminish the production of PHB. When tested manometrically, no utilization of PHB itself was found, but isolate 1.8 and ATCC 13872, the only strains investigated in this regard, did grow in CHB medium supplemented with either $\mathbf{0 . 2 5} \%$ or $\mathbf{0 . 5} \%(\mathrm{w} / \mathrm{v})$ sodium- $\beta$-hydroxybutyrate.

Table 6. Data on free lipid granule and poly- $\beta$-hydroxybutyric acid $(\mathbf{P H B})$ content of 6-day CHM culture of Caryophanon latum isolate 1.8

Two $15 \mathrm{ml}$. portions were removed from the 6-day culture and allowed to settle for about $24 \mathrm{hr}$. The supernatant granule sample was taken from one; the other was resuspended to provide a sample representative of the whole culture. The clarified medium was prepared by centrifugation at $11,000 \mathrm{~g}$ for $15 \mathrm{~min}$.

\section{Culture fraction}

Supernatant granules

Suspended culture

Clarified medium

Total culture crop dry wt.

Chloroform extract dry wt.

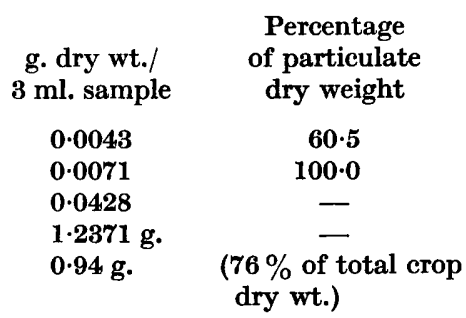

Percentage

dry weight

$60 \cdot 5$

$100 \cdot 0$

dry wt.)

Poly- $\beta$-hydroxybutyrate : $80 \%$ of chloroform extract, $61 \%$ of total crop dry wt.

\section{General properties of Caryophanon latum}

In contrast to the reports of previous workers (with the possible exception of Tuffery, 1953), in the present work Caryophanon latum was found to be Grampositive. PYA slope cultures, stained at $13,15,19,24$ and $48 \mathrm{hr}$., were uniformly Gram-positive when the Hucker modification of the Gram stain, or a further modification with the crystal violet concentration decreased from 2 to $0.5 \%(\mathrm{w} / \mathrm{v})$ and an increase in decolorization time to 75 sec. were used.

Caryophanon latum produced catalase and did not reduce nitrate to nitrite, produce indole, or liquefy gelatin. CYA shake tubes showed growth of C. latum only at the surface, with the exception of culture isolates 1.2 and 1.8 which grew to a depth of about $1 \mathrm{~mm}$. PYA slope cultures grew at $10^{\circ}, 19^{\circ}, 2^{\circ}$, and $37^{\circ}$, none grew at $45^{\circ}$ and $25^{\circ}$ seemed optimal. Cultures of C.latum ATCC 12871 survived for 9 weeks (not tested further) on PYA slopes at $-20^{\circ}, 4^{\circ}, 25^{\circ}$ and $37^{\circ}$. C. latum cultures survived for 9 months (not tested further) at room temperature (about $20^{\circ}$ ) on tightly enclosed PYA slopes. Cultures have also survived lyophilization for one year.

Spheroplasts (protoplasts?) were produced with lysozyme from culture ATCC 12871. Continuing work (F. Tyeryar, private communication) has indicated a general susceptibility of Caryophanon latum to the action of lysozyme. C. latum 
cultures were resistant to a variety of sulfa drugs but not antibiotics such as penicillin, bacitracin, tetracycline and others. Crystal violet and sodium azide also were inhibitory.

\section{DISCUSSION}

Although isolated to date only from cow dung, Caryophanon latum does not appear to be an intestinal inhabitant. The obligate aerobic nature of $C$. latum provides perhaps the most convincing reason why it could not be an inhabitant of the anaerobic intestinal tract. Like Pringsheim \& Robinow (1947) and Weeks \& Kelley (1958) we were not able to isolate $C$. latum from freshly voided dung, i.e. dung which had not come in contact with soil, hay, grass, dust or insects. It would seem likely that these materials are natural harbourers of $C$. latum and that only by chance does the organism reach the cow dung wherein it rapidly proliferates. The fatty acid content (e.g. acetic and butyric acids) and slightly alkaline $\mathrm{pH}$ value, about $7 \cdot 5$, of cow dung are probably major factors responsible for allowing the proliferation of $C$. latum; medium CHM is similar to cow dung in these characters.

A greater oxygen uptake (about $2 \cdot 5$ times) on butyric acid might be expected than on acetic acid. The equal oxygen uptakes obtained in the present work might be explained either of two ways; it might be argued that a larger percentage of butyrate than of acetate was assimilated into storage material. Measurements of $\mathrm{O}_{2}$ uptake with butyrate (up to $24 \mathrm{hr}$.) did not exceed that observed with acetate at any time. In addition, $\mathrm{O}_{2}$ uptake on fatty acids $\mathrm{C} 2$ through $\mathrm{C}_{4}$ was linear throughout the experimental period. A second and more interesting possibility is that butyrate might have protected the stored poly- $\beta$-hydroxybutyric acid in the cells from being metabolized (compare Doudoroff \& Stanier, 1959), while acetate conferred no such protection; thus the endogenous metabolism on butyrate might have been far less than on acetate. The high endogenous activity obtained in the present experiments serves as the only indication that $C$. latum can utilize poly- $\beta$-hydroxybutyrate.

This compound has been demonstrated in a variety of bacteria (Lemoigne, 1927; Forsyth, Hayward \& Roberts, 1958; Levine \& Wolochow, 1959; Doudoroff \& Stanier, 1959). The amount of poly- $\beta$-hydroxybutyrate shown in Caryophanon latum in the present work is somewhat greater than that reported for any other bacterium. However, it should be considered that the amount of accumulation of a storage product such as poly- $\beta$-hydroxybutyrate is a reflexion of the chemical environment of the organism, as discussed by Herbert (1961). Our fluid medium (CHM) has a high carbon: nitrogen ratio, providing conditions under which heavy accumulation of carbon storage products (such as poly- $\beta$-hydroxybutyrate) would be expected.

The nutritional and physiological characters of Caryophanon latum revealed thus far do not indicate that this giant bacterium differs in any basic way from other heterotrophic eubacteria. The present work has not been concerned with the cytology of $C$. latum but, considering the structure as elucidated by Pringsheim \& Robinow (1947), it seems to us that this structure differs from that observed in the multicellular forms of bacilli only in regard to the frequency of septation, rather in the nature or order of formation. If this be so, it seems that a rather convincing argument could be presented for classifying $C$. latum among the eubacteria rather than in a separate order. 

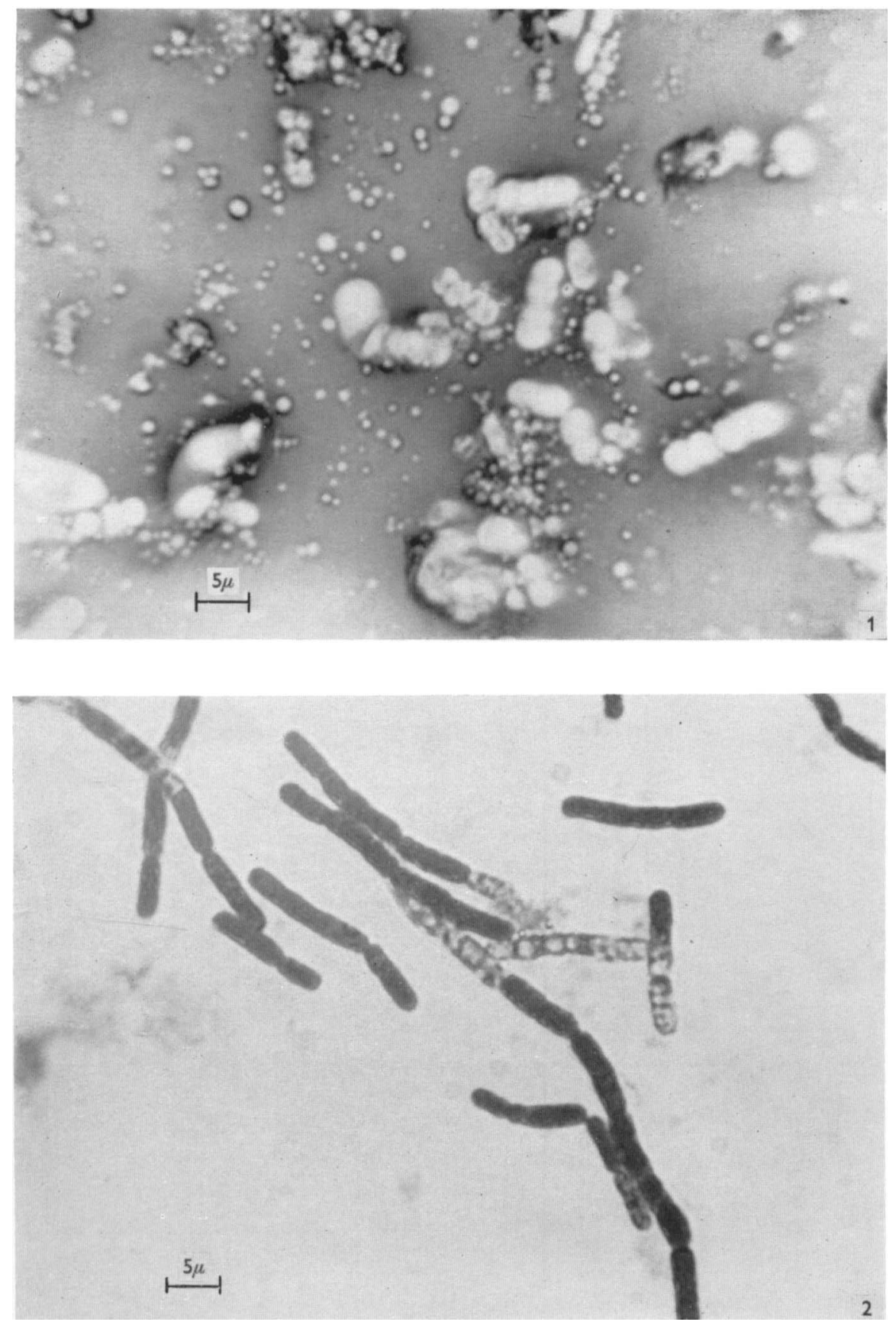
This work was supported in part by a summer fellowship awarded by the National Science Foundation, and by a training grant from the Department of Health, Education and Welfare (2G-615-MTC). This paper is Scientific Article No. A-938 contribution no. 3296 of the Maryland Agricultural Experiment Station.

\section{REFERENCES}

Bisset, K. A. (1953). The cytology of Caryophanon latum. Mycologia, 45, 790.

DeLamater, E. D. (1952). Preliminary observations on the occurrence of mitosis in Caryophanon latum. Mycologia, 44, 203.

Doudonoff, N. \& Stanier, R. Y. (1959). Role of poly- $\beta$-hydroxybutyric acid in the assimilation of organic carbon by bacteria. Nature, Lond. 183, 1440.

Ellinghausen, H. C. \& Pelczar, M. J. (1957). Effect of diphenylamine on pigment production by Neisseria. J. Bact. 73, 130.

Forsyth, W. G. C., Hayward, A. C. \& Roberts, J. B. (1958). Occurrence of poly$\beta$-hydroxybutyric acid in aerobic Gram negative bacteria. Nature, Lond. 182, 800.

HerberT, D. (1961). The chemical composition of micro-organisms as a function of their environment. Symp. Soc. gen. Microbiol. 11, 391.

LAW, J. H. \& Slepecky, R. A. (1961). Assay of poly- $\beta$-hydroxybutyric acid. J. Bact. 82, 33.

Lemoigne, M. (1927). Études sur l'autolyse microbienne. Origine de l'acide $\beta$-oxybutyrique formé par autolyse. Ann. Inst. Pasteur, 41, 148.

Levine, H. B. \& Wolochow, H. (1959). Occurrence of poly- $\beta$-hydroxybutyrate in Pseudomonas pseudomallei. J. Bact. 79, 305.

Manual of Microbiological Methods (1957). Society of American Bacteriologists. New York, N.Y.: McGraw-Hill.

May, P. S. \& Gershenfeld, L. (1955). Caryophanon latum-the effect of selected nutrients on its growth in a liquid synthetic medium. Bact. Proc. p. 48.

MurRay, R. G. E. (1957). Direct evidence for a cytoplasmic membrane in sectioned bacteria. Canad. J. Microbiol. 3, 531.

Peshroff, M. A. (1940). Phylogenesis of new microbes, Caryophanon latum and Caryophanon tenue, organisms which are intermediate between the blue-green algae and the bacteria. (Summary in English.) J. gen. Biol., Moscorw, 1, 598.

Peshroff, M. A. (1946). Fine structure and mechanism of division of the 'nuclei' of the bacterium Caryophanon latum. Nature, Lond. 157, 137.

Pringsheim, E. G. \& Robinow, C. F. (1947). Observations on two very large bacteria, Caryophanon latum Peshkoff and Lineola longa (nomen provisorium). J. gen. Microbiol. $1,267$.

Sall, T. \& Mudd, S. (1955). A cytological study of Caryophanon latum. J. gen. Microbiol. 12,47 .

Slepecky, R. A. \& Law, J. H. (1960). A rapid spectrophotometric assay of $\alpha$-, $\beta$-unsaturated acids and $\beta$-hydroxy acids. Analyt. Chem. 32, 1697.

Tomcsik, J. \& Grace, J. B. (1955). Bacterial cell walls as revealed by the specific cell-wall reaction and by direct staining with alcian blue. J. gen. Microbiol. 13, 105.

Tuffery, A. A. (1953). The morphology and systematic position of Caryophanon. Proc. 6th int. Congr. Microbiol. 1, 77.

WeEKS, O. B. \& KeLLeY, L. M. (1958). Observations on the growth of the bacterium Caryophanon latum. J. Bact. 75, 326.

Williamson, D. H. \& Wilkinson, J. F. (1958). The isolation and estimation of the poly$\beta$-hydroxybutyrate inclusions of Bacillus species. J. gen. Microbiol. 19, 198.

\section{EXPLANATION OF PLATE 1}

Fig. 1. Nigrosin preparation of the sediment (24 hr. settling) in a 6-day CHM culture of Caryophanon latum isolate 1.8. Note the free poly- $\beta$-hydroxybutyrate granules and the disintegrating and misshapen trichomes. $\times \mathbf{1 3 3 0}$.

Fig. 2. Burdon lipid stain of a 24 hr. CHM culture of Caryophanon latum isolate 1.8. The dark areas represent lipid. $\times 1330$. 